\title{
Studying Bacterial Diversity of Verhniy Kaban Lake by 16S rRNA Analysis
}

\author{
${ }^{1}$ Anastasia Kharchenko, ${ }^{2}$ Anthony Elias Sverdrup, ${ }^{3}$ Ludmila Frolova \\ ${ }^{1-3}$ Kazan Federal University \\ Email:Lucie.Frolova@gmail.com
}

Received: $2^{\text {th }}$ August 2019, Accepted: $30^{\text {th }}$ September 2019, Published: $31^{\text {st }}$ October 2019

\begin{abstract}
The article presents the results of a study of the bacterial diversity of Verhniy Kaban Lake (Kazan, Russia) for 2016-2017 using the marker gene $16 S$ rRNA of hydrobionts based on the next-generation sequencing method. Verhniy Kaban Lake with Sredniy Kaban Lake and Nizhniy Kaban Lake are included in the system of Kaban Lakes. The lakes are located in the center of a big industrial city and experience anthropogenic load. According to ecological studies, Kaban Lakes are polluted lakes. The sequences of 16S rRNA Bacteria of freshwater Verhniy Kaban Lake in 2016-2017 were submitted to the international SRA database on the NCBI website in the fastq format with numbers SRR7510928, SRR7465228, SRR7516245. A comparative analysis of metagenomic data showed a significant change in bacterial diversity over the years. A total of 110467 (2016) and 87093 (2017) high-quality reads were obtained; 30\% (2016) and 32\% (2017) of the bacterial population was classified to the genus level, while $0.4 \%$ (2017) was classified to the species level. A total of 19 species of Bacteria were identified, among which the bacteria most commonly found in the gastrointestinal tract of humans and/or animals are most common. These types of bacteria can pose a threat to human health. Therefore, the species composition of the bacterial community must be taken into account when assessing the ecological state of water bodies.
\end{abstract}

\section{Keywords}

Monitoring, Gene 16S rRNA, Next-Generation Sequencing, Freshwater Lake, Bacteria

\section{Introduction}

The objective of microbiomes research is to characterize the diversity of microorganisms found in the environment. It is known that biological communities respond to numerous factors of anthropogenic and natural environmental changes. Identification of the nonspecific response of living organisms to changing environmental conditions, for example, pollution or purification is used to assess the ecological state of ecosystems [1]. Free-floating freshwater bacteria are at the center of biogeochemical cycles and affect water quality. Currently, there is insufficient information on the composition of the community and the ecology of lake bacteria [2, 3].

Recently, the cost reducing of next-generation sequencing technology has allowed identifying large numbers of organisms. We used this technology to identify zooplankton by the COl gene and phytoplankton by the $r b c L$ gene to assess the ecological state of freshwater Verhniy Kaban Lake [4, 5].

The dominant tool for studying microbial ecology is sequencing of the $16 S r R N A$ gene [6]. The advantages of the $16 S$ $r R N A$ gene sequencing are its presence in all prokaryotes, the gene rarely undergoes horizontal transfer, and also has a higher degree of conservation than genes encoding enzymes [7]. Unfortunately, when a $16 S r R N A$ gene is selected as a marker for sequencing, a large number of organisms are not determined to the exact species.

The article presents the results of a study of the bacterial diversity of Verhniy Kaban Lake (Kazan, Russia) for 2016-2017 using the marker gene $16 S r R N A$ of hydrobionts based on the next-generation sequencing method. Verhniy Kaban Lake with Sredniy Kaban Lake and Nizhniy Kaban Lake are included in the system of Kaban Lakes. The lakes are located in the center of a big industrial city and experience anthropogenic load. According to ecological studies, Kaban Lakes are polluted.

\section{Methods}

Sampling from Verhniy Kaban Lake (Kazan) was carried out in 2016-2017 in accordance with standard hydrobiological methods [8].

Isolation of DNA from the precipitate obtained by centrifugation of $50 \mathrm{ml}$ of the sample at a rate of $10,000 \mathrm{~g}$ for $15 \mathrm{~min}$ was carried out using the FAST DNA Kit (MP biomedicals) according to the manufacturer's protocol. Amplification of the isolated DNA was performed by Phusion High-Fidelity DNA polymerase (Thermo Fisher) using the Eurogen primers (http://evrogen.ru) (Table 1).

\begin{tabular}{|l|l|}
\hline Primers & Sequences \\
\hline 16SF_I (forward) & 5'-tcgtcggcagcgtcagatgtgtataagagacagcctacgggnggcwgcag-3' \\
\hline 16SR_I (reverse) & 5'-gtctcgtgggctcggagatgtgtataagagacaggactachvgggtatctaatcc-3' \\
\hline
\end{tabular}

Table 1: Primers for PCR of 16S rRNA gene 
Purification of the PCR products was carried out with Agencourt AMPure XP beads (Beckman Coulter), followed by a second PCR for indexing the samples (Nextera XT indices).

The resulting DNA libraries were sequenced on an Illumina MiSeq (MiSeq Reagent kit v3). After filtering the reads by quality, trimming the service sequences, and removing the chimeric sequences, the resulting nucleotide sequences were aligned with the BLAST program to establish the taxonomic composition. Metagenomic data were submitted to the international SRA database on NCBI website in the fastq format with numbers SRR7510928, SRR7465228, SRR7516245 [9]. The Krona chart (https://github.com/marbl/Krona/wiki) and GraphPad (https://www.graphpad.com) software were used for charts.

\section{Results and Discussion}

Krona chart of the bacteria represented by $16 S$ rRNA gene amplicon-based bacterial diversity by reads The percentage distributions of Bacteria of Verhniy Kaban Lake by reads for 2016 and 2017, respectively, are presented in Fig. 1-2. Each circle represents the phylum, class, order, family and genus from the inside to the outside of the circle, respectively, indicated by percent diversity based on the absolute number of representative bacteria.

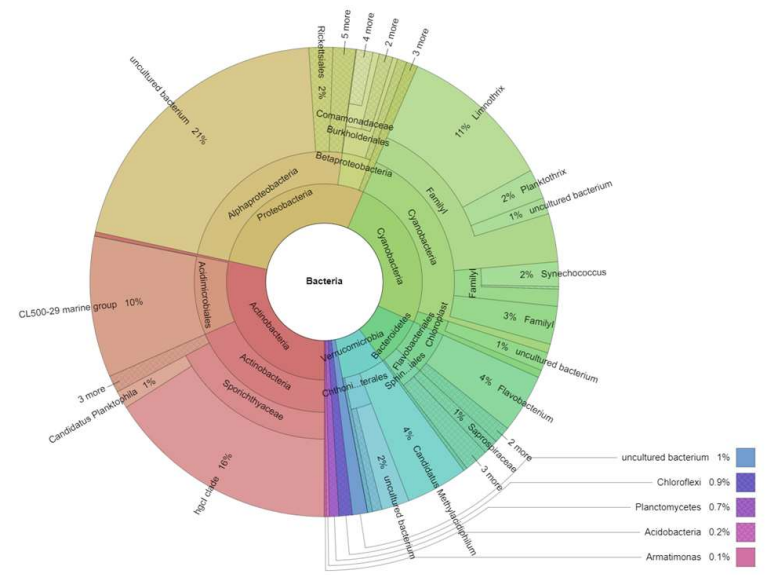

Figure 1: The Percentage of $16 S \mathrm{rRNA}$ Bacteria reads of Verhniy Kaban Lake (2016)

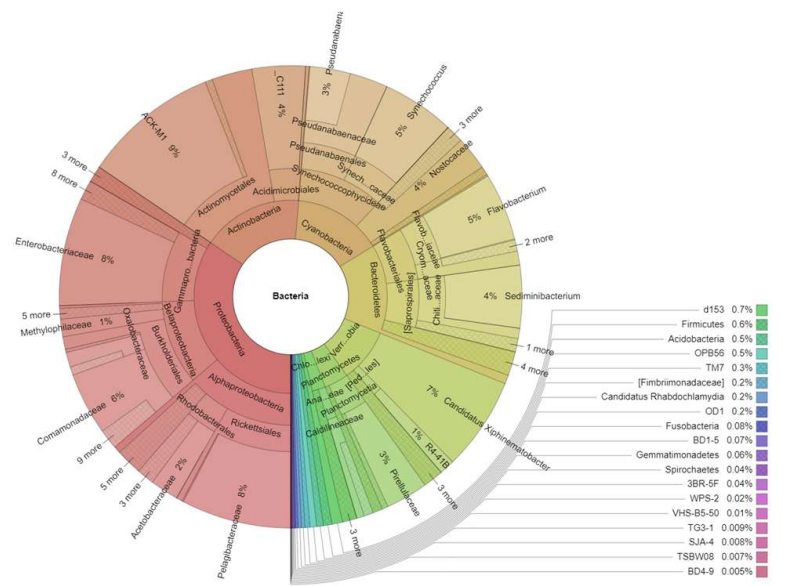

Figure 2: The Percentage of $16 S r R N A$ Bacteria reads of Verhniy Kaban Lake (2017)

The percentage of $16 \mathrm{~S}$ rRNA Bacteria of Verhniy Kaban Lake by phylum

The percentage of $16 S$ rRNA Bacteria of Verhniy Kaban Lake by phylum (2016-2017) is shown in Fig. 3. None of identified Bacteria phylums are unique for 2016, 62.5\% phylums are common for 2016-2017 and 37.5\% are unique for bacterial community of 2017 (Fig. 3). Phylums Acidobacteria, Actinobacteria, Armatimonadetes, Bacteroidetes, Chlorobi, Chloroflexi, Cyanobacteria, Planctomycetes, Proteobacteria and Verrucomicrobia are common for 2016-2017. 


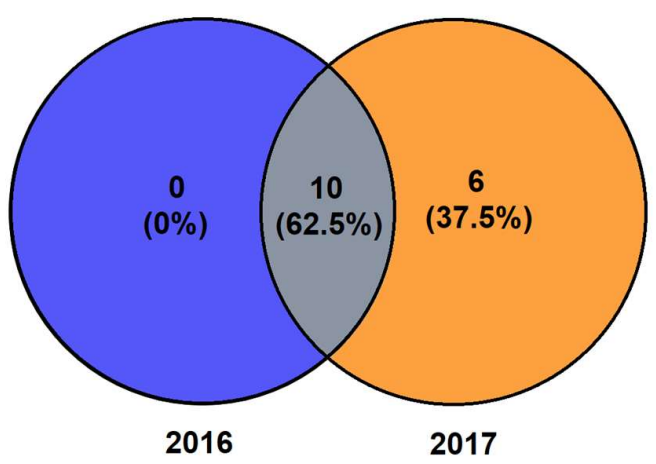

Figure 3: The Percentage of $16 S r R N A$ Bacteria reads of Verhniy Kaban Lake by phylum (2016-2017)

The percentage of $16 \mathrm{~S}$ rRNA Bacteria reads of Verhniy Kaban Lake by phylum (2016-2017) is shown in Figure 4. As Fig. 4 shows, the most numerous at the phylum level, respectively, by year, are Proteobacteria $(27.5 \% / 33.3 \%)$, Actinobacteria (27.9\%/16.3\%), Cyanobacteria (24.7\%/16.8\%), Bacteroidetes $(8 \% / 14.4 \%)$ and Verrucomicrobia $(7 \% / 8.7 \%)$.

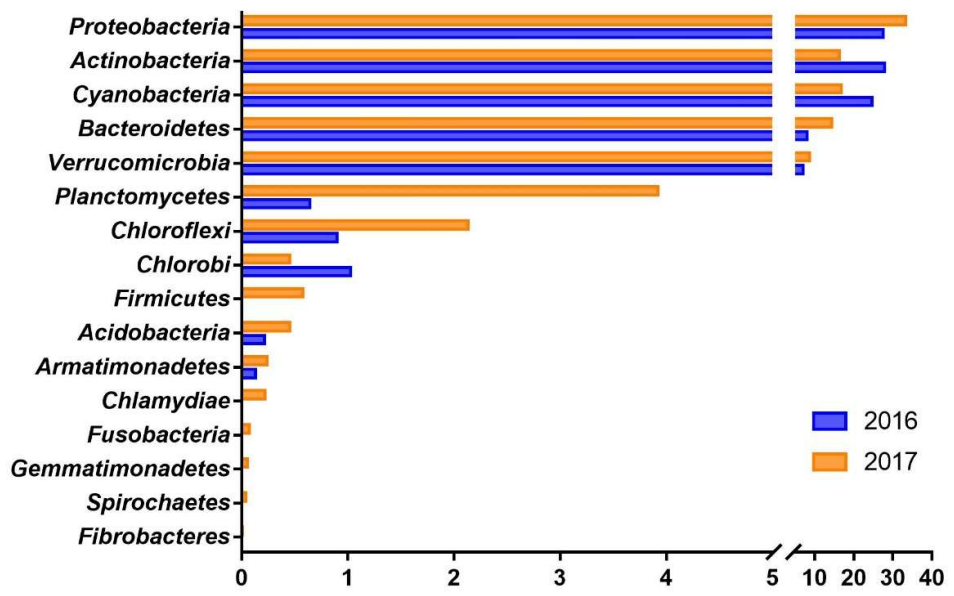

Figure 4: The Percentage of $16 S$ rRNA Bacteria reads of Verhniy Kaban Lake by phylum (2016-2017)

The percentage of species diversity of $16 S$ rRNA Bacteria of Verhniy Kaban Lake by phylum (2016-2017) is shown in Figures 5. As Fig. 5 shows, the most numerous at the phylum level, respectively, by year, are Proteobacteria (40.6\%/47.4\%), Bacteroidetes (20.3\%/12\%), Cyanobacteria (10.9\%/9.3\%), Actinobacteria $\quad(10.9 \% / 8.7 \%)$, Verrucomicrobia (7.2\%/3.4\%), as well as Firmicutes (6.5\%) only for 2017.

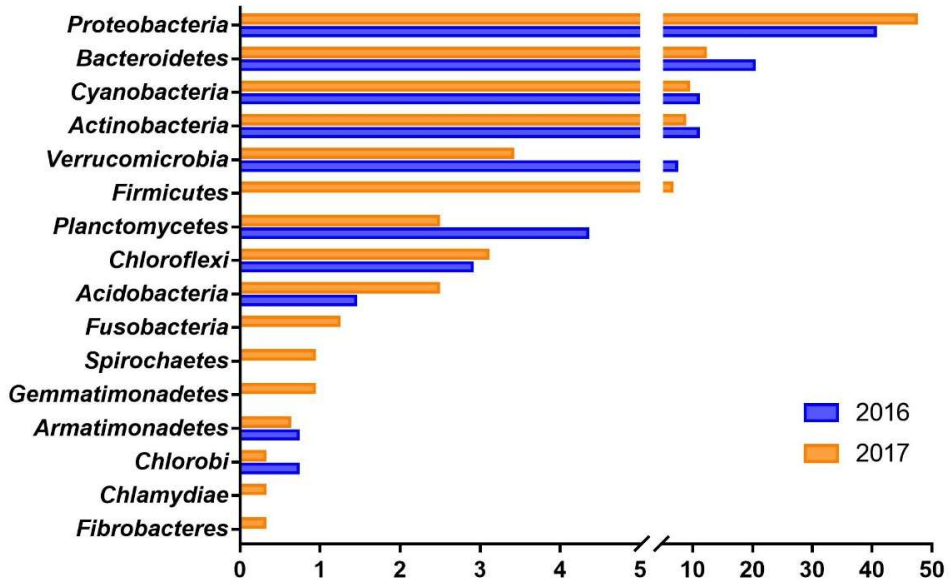

Figure 5: The Percentage of Species Diversity of $16 S r R N A$ Bacteria of Verhniy Kaban Lake by phylum (20162017) 
The percentage of $16 S$ rRNA Bacteria of Verhniy Kaban Lake by class

The percentage of species diversity of $16 \mathrm{~S}$ rRNA Bacteria of Verhniy Kaban Lake by class (2016-2017) is shown in Figure 6. The most represented classes for the bacterial community of Verhniy Kaban Lake in 2016 in terms of reads are Alphaproteobacteria (33.9\%), Actinobacteria (26.3\%) and Acidimicrobiia (13.9\%), and in terms of species are Alphaproteobacteria (17.3\%) Betaproteobacteria (17.3\%) and Sphingobacteriia (12.3\%). The most represented classes for the bacterial community of Verhniy Kaban Lake in 2017 in terms of reads are Alphaproteobacteria (13.9\%), Actinobacteria (12.9\%), Betaproteobacteria (10.7\%) and Synechococcophycideae (10.7\%), and in terms of species are Alphaproteobacteria (16.4\%), Betaproteobacteria (13.5\%), Gammaproteobacteria $(11.3 \%)$.

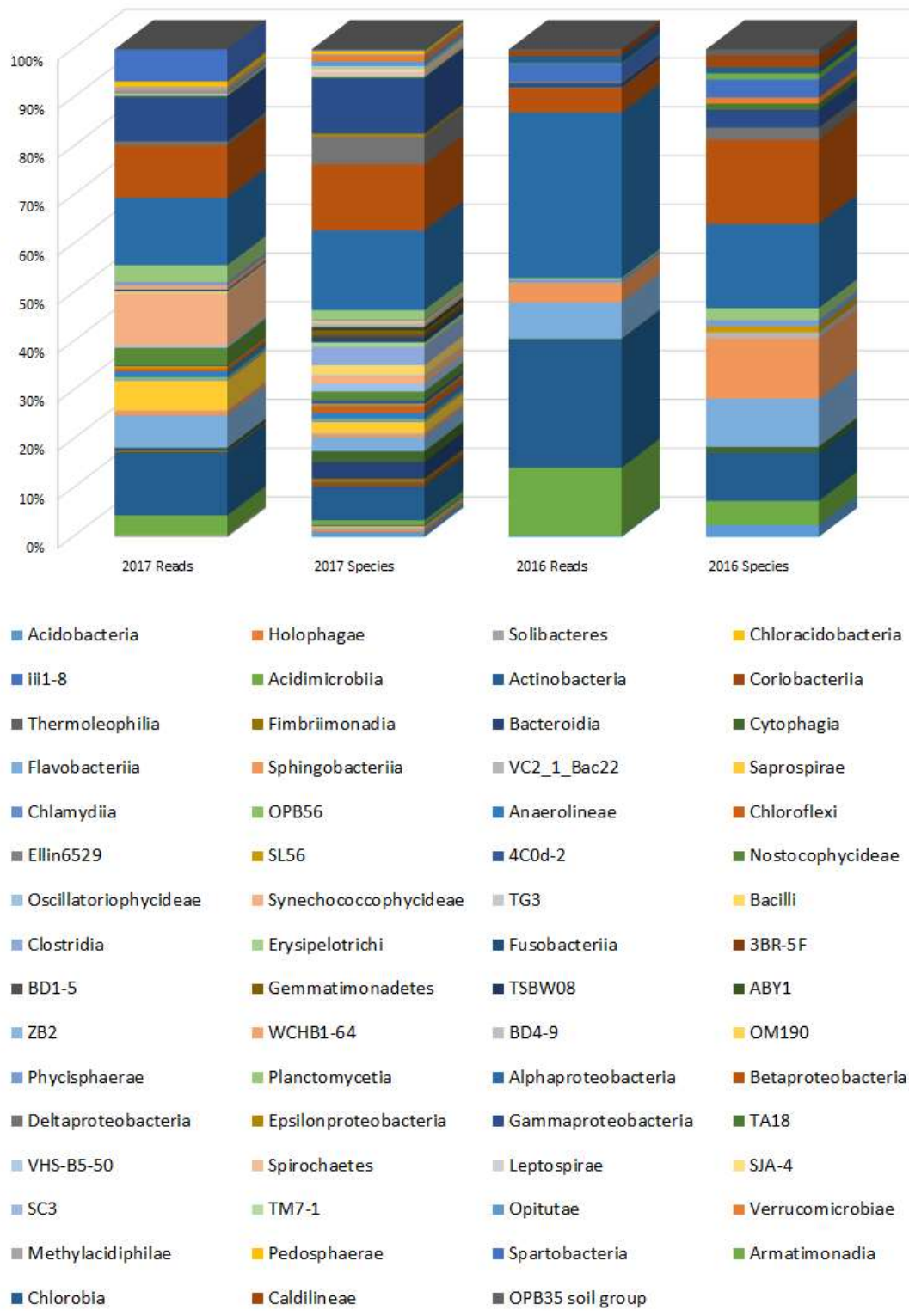

Figure 6: The Percentage of Species Diversity of $16 \mathrm{~S} r \mathrm{RNA}$ Bacteria of Verhniy Kaban Lake by Class (20162017)

The percentage of $16 S$ rRNA Bacteria of Verhniy Kaban Lake by order

The percentage of $16 S$ rRNA Bacteria of Verhniy Kaban Lake by order (2016-2017) is shown in Figure 7. 10.7\% of identified Bacteria orders are unique for 2016, 26.7\% orders are common for 2016-2017 and 62.7\% are unique for bacterial community of 2017 (Fig.7). Orders Acidimicrobiales, Cytophagales, Flavobacteriales, Sphingobacteriales, Caldilineales, Phycisphaerales, Planctomycetales, Caulobacterales, Rhizobiales, Rhodobacterales, Rickettsiales, 
Sphingomonadales, Burkholderiales, Methylophilales, Myxococcales, Syntrophobacterales, Enterobacteriales, Methylococcales, Xanthomonadales and Verrucomicrobiales are common for 2016-2017.

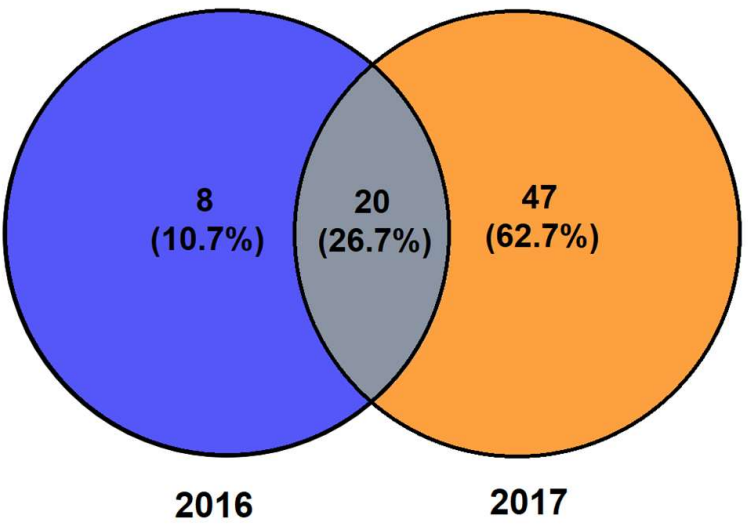

Figure 7: The Percentage of 16S rRNA Bacteria of Verhniy Kaban Lake by Order (2016-2017)

The percentage of $16 S$ rRNA Bacteria of Verhniy Kaban Lake by order on 2016: in terms of (A) reads; (B) species shown in Figure 8. As Fig. 8 shows, the most numerous at the order level, respectively, in terms of reads, are Frankiales (16.9\%), Acidimicrobiales (9.6\%), Flavobacteriales (5.1\%); in terms of species: Burkholderiales (16.2\%), Sphingobacteriales (15.2\%), Flavobacteriales (10.1\%).
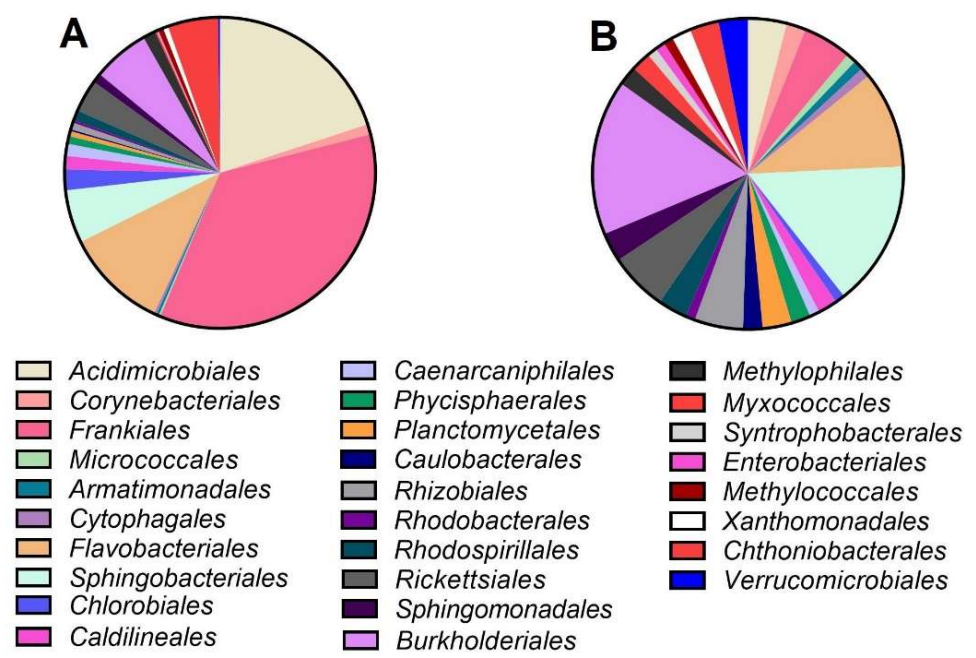

Figure 8: The Percentage of 16S rRNA Bacteria of Verhniy Kaban Lake by Order on 2016: in Terms of (A) Reads; (B) Species

The percentage of 16S rRNA Bacteria of Verhniy Kaban Lake by order on 2017: in terms of (A) reads; (B) species shown in Figure 9. As Fig. 9 shows, the most numerous at the order level, respectively, in terms of reads, are Actinomycetales (12.4\%), Burkholderiales (8.2\%), Rickettsiales (7.9\%), Enterobacteriales (7.3\%), Flavobacteriales (6.3\%), Chthoniobacterales (6.3\%), in terms of species: Burkholderiales (8.5\%), Actinomycetales (7.8\%), Rhizobiales (6\%), Clostridiales (4.2\%), Bacteroidales (3.9\%), Rhodobacterales (3.9\%) Sphingomonadales (3.9\%). 

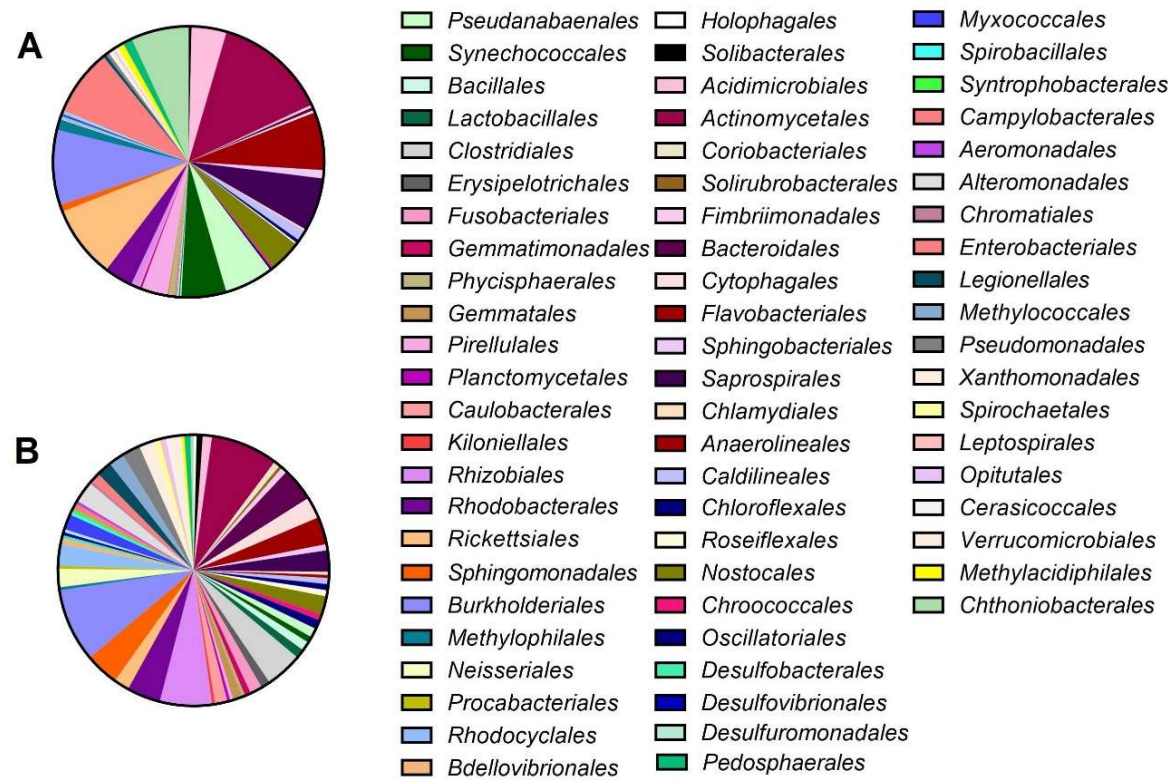

Figure 9: The Percentage of $16 S$ rRNA Bacteria of Verhniy Kaban Lake by Order on 2017: in Terms of (A) Reads; (B) Species

The percentage of 16 S rRNA Bacteria of Verhniy Kaban Lake by family

The percentage of $16 S$ rRNA Bacteria of Verhniy Kaban Lake by family (2016-2017) is shown in Fig. 10. 14.4\% of identified Bacteria families are unique for 2016, 14.4\% families are common for 2016-2017 and $71.2 \%$ are unique for bacterial community of 2017 (Fig. 10). Families Flavobacteriaceae, Comamonadaceae, Cryomorphaceae, Chitinophagaceae, Saprospiraceae, Caldilineaceae, Burkholderiaceae, Methylophilaceae, Mycobacteriaceae, Acetobacteraceae, Sphingomonadaceae, Planctomycetaceae, Alcaligenaceae, Methylocystaceae, Rhodobacteraceae, Microbacteriaceae, Hyphomonadaceae, Verrucomicrobiaceae, Rickettsiaceae and Enterobacteriaceae are common for 2016-2017.

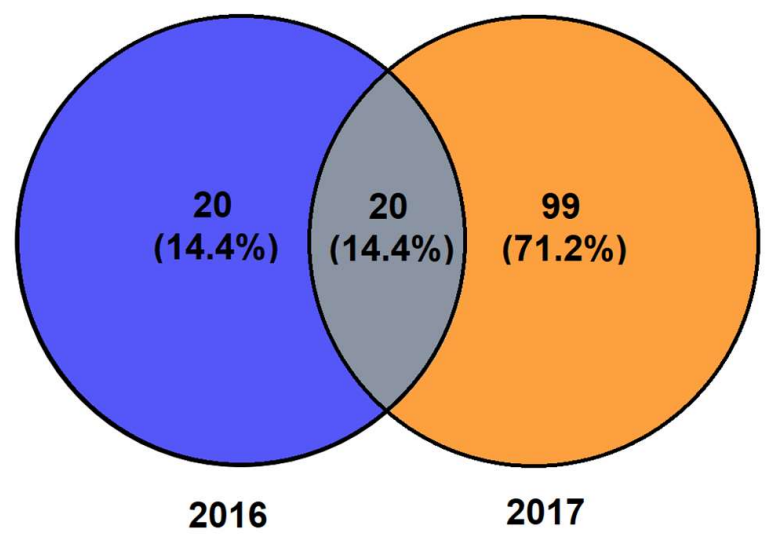

Figure 10: The Percentage of $16 S$ rRNA Bacteria of Verhniy Kaban Lake by Family (2016-2017)

Among the family, over 1\% were Comamonadaceae (1.5\%/5.6\%) and Flavobacteriaceae (4/4.6\%) in 2016-2017; LD12 (20.1\%), Sporichthyaceae (16.9\%), Acidimicrobiaceae (9.5\%) in 2016; ACK-M1 (9.2\%), Pelagibacteraceae (7.4\%), Enterobacteriaceae (7.3\%) in 2017 (Fig.11). 


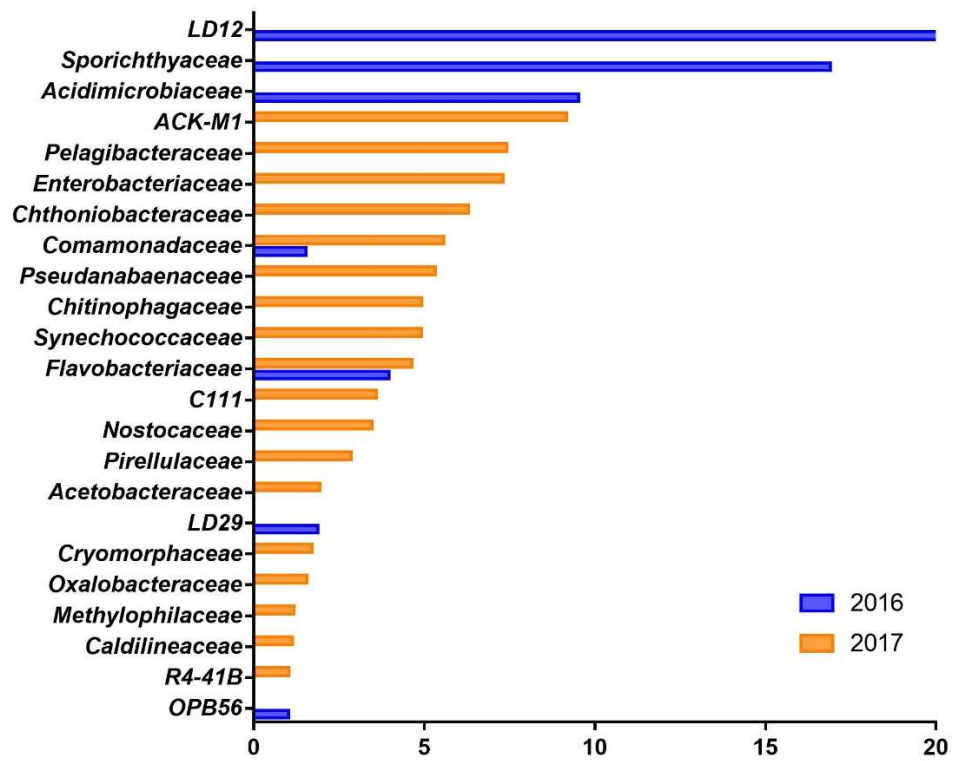

Figure 11: The Percentage of $16 S$ rRNA Bacteria of Verhniy Kaban Lake by Family Over 1\% (2016-2017)

The most represented families of the bacterial community of Verhniy Kaban Lake in 2016 were: LD12 (20.1\%), Sporichtyaceae (16.9\%), Acidimicrobiaceae (9.5\%) and Flavobacteriaceae (4\%) (Fig. 12).

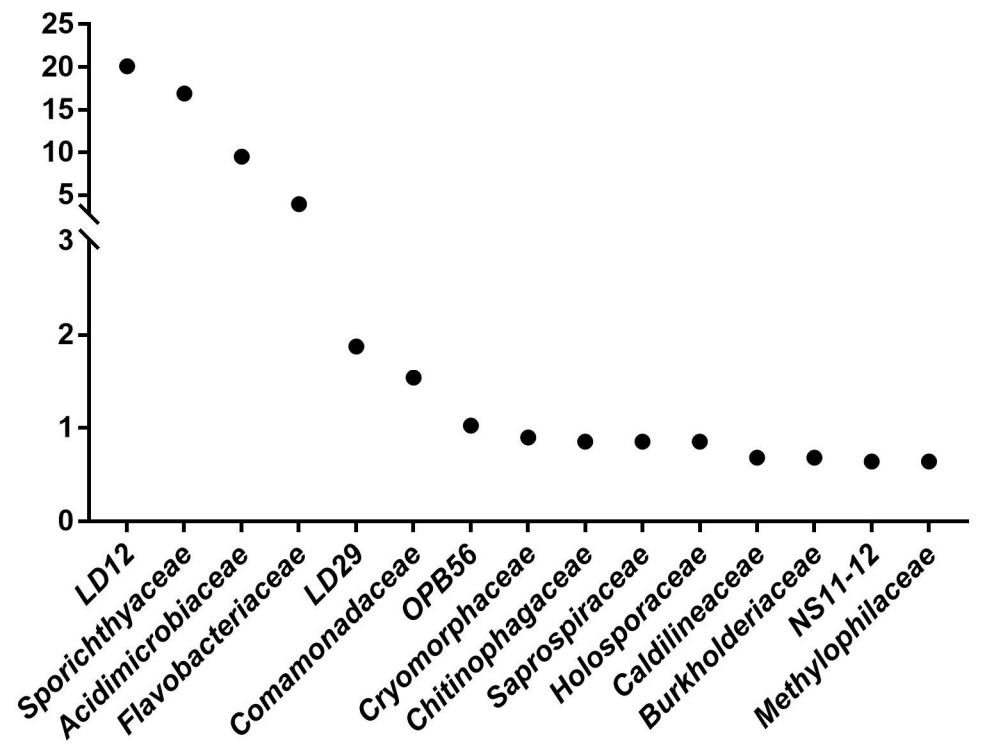

Figure 12: Top-15 Families of $16 S$ rRNA Bacteria of Verhniy Kaban Lake (2016)

The most represented families of the bacterial community of Verhniy Kaban Lake in 2017 were: $A C K-M 1$ (9.2\%), Pelagibacteraceae (7.4\%), Enterobacteriaceae (7.3\%), Chthoniobacteraceae (6.3\%), Comamonadaceae (5.6\%), Pseudanabaenaceae (5.3\%), Chitinophagaceae (4.9\%), Synechococcaceae (4.9\%) (Fig. 13). 


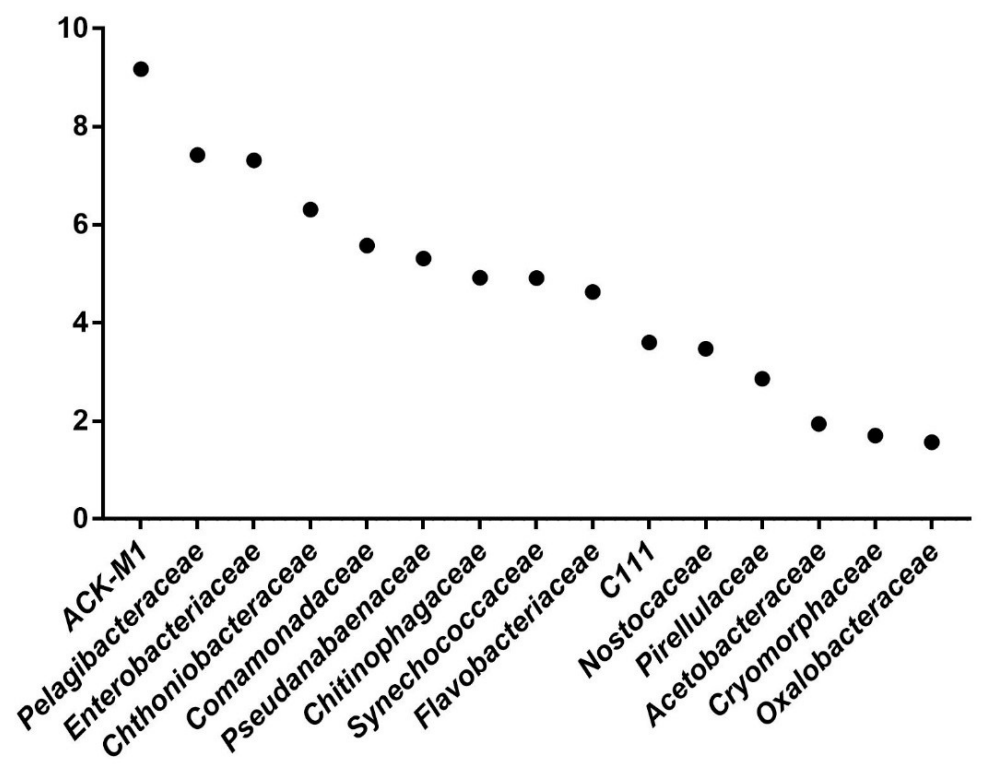

Figure 13: Top-15 Families of $16 S$ rRNA Bacteria of Verhniy Kaban Lake (2017)

The percentage of $16 S$ rRNA Bacteria of Verhniy Kaban Lake by genus

The percentage of $16 S$ rRNA Bacteria of Verhniy Kaban Lake by genus (2016-2017) is shown in Fig. 14. 15.9\% of identified Bacteria genus are unique for 2016, 8.3\% genus are common for 2016-2017 and 75.9\% are unique for bacterial community of 2017 (Fig. 14). Genus Mycobacterium, Fluviicola, Flavobacterium, Sediminibacterium, Lewinella, Synechococcus, Planktothrix, Novosphingobium, Limnobacter, Polynucleobacter, Limnohabitans and Variovorax are common for 2016-2017.

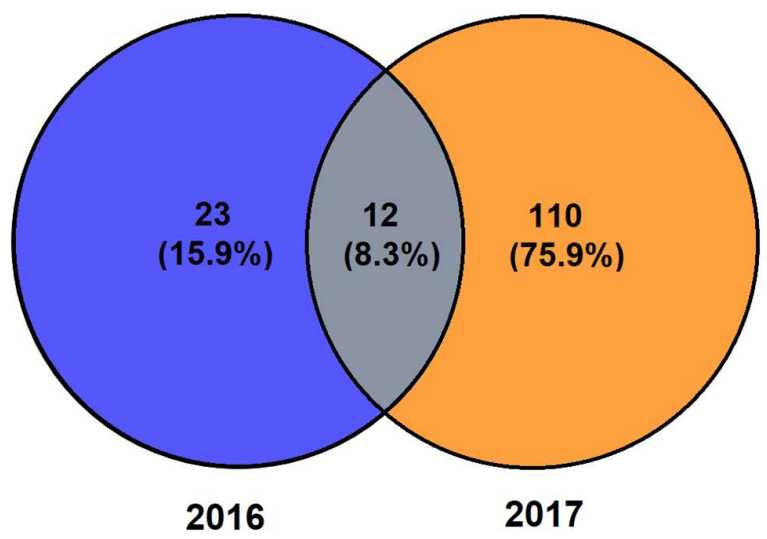

Figure 14: The Percentage of $16 S$ rRNA Bacteria of Verhniy Kaban Lake by Genus (2016-2017)

The percentage of $16 S$ rRNA Bacteria of Verhniy Kaban Lake by species

Table 2 shows the classification of bacterial organisms in Verhniy Kaban Lake. 


\begin{tabular}{|c|c|c|c|c|c|}
\hline Phylum & Class & Order & Family & Species & $\%$ \\
\hline \multirow[t]{5}{*}{ Actinobacteria } & \multirow[t]{4}{*}{ Actinobacteria } & \multirow[t]{4}{*}{ Actinomycetales } & \multirow[b]{2}{*}{$\begin{array}{c}\text { Micro- } \\
\text { bacteriaceae }\end{array}$} & Agromyces mediolanus $^{I}$ & 0.00053 \\
\hline & & & & $\begin{array}{c}\text { Candidatus Aquiluna } \\
\text { rubra }^{2}\end{array}$ & 0.00010 \\
\hline & & & Micrococcaceae & Micrococcus luteus $^{3}$ & 0.00012 \\
\hline & & & $\begin{array}{c}\text { Propioni- } \\
\text { bacteriaceae }\end{array}$ & Propionibacterium acnes ${ }^{4}$ & 0.00024 \\
\hline & Coriobacteriia & Coriobacteriales & $\begin{array}{c}\text { Corio- } \\
\text { bacteriaceae }\end{array}$ & Collinsella aerofaciens ${ }^{5}$ & 0.00013 \\
\hline \multirow[t]{3}{*}{ Bacteroidetes } & \multirow[t]{2}{*}{ Bacteroidia } & \multirow[t]{2}{*}{ Bacteroidales } & \multirow[b]{2}{*}{ Prevotellaceae } & Prevotella copri $^{6}$ & 0.00006 \\
\hline & & & & Prevotella stercorea $^{7}$ & 0.00007 \\
\hline & Flavobacteriia & Flavobacteriales & $\begin{array}{c}\text { Flavo- } \\
\text { bacteriaceae }\end{array}$ & $\begin{array}{c}\text { Flavobacterium } \\
\text { succinicans } \\
\end{array}$ & 0.00001 \\
\hline \multirow[t]{4}{*}{ Firmicutes } & Bacilli & Lactobacillales & Streptococcaceae & Streptococcus luteciae $^{9}$ & 0.00014 \\
\hline & \multirow[t]{2}{*}{ Clostridia } & \multirow[t]{2}{*}{ Clostridiales } & Peptococcaceae & $\begin{array}{c}\text { Desulfosporosinus } \\
\text { meridiei }^{10}\end{array}$ & 0.00051 \\
\hline & & & Ruminococcaceae & $\begin{array}{c}\text { Faecalibacterium } \\
\text { prausnitzii }^{11}\end{array}$ & 0.00028 \\
\hline & Erysipelotrichi & Erysipelotrichales & $\begin{array}{l}\text { Erysipelo- } \\
\text { trichaceae }\end{array}$ & Eubacterium biforme $e^{12}$ & 0.00052 \\
\hline Fusobacteria & Fusobacteriia & Fusobacteriales & Fusobacteriaceae & Cetobacterium somerae $^{13}$ & 0.00018 \\
\hline \multirow[t]{5}{*}{ Proteobacteria } & \multirow[t]{2}{*}{$\begin{array}{c}\text { Alpha- } \\
\text { proteobacteria }\end{array}$} & Caulobacterales & Caulobacteraceae & $\begin{array}{c}\text { Brevundimonas } \\
\text { diminuta }^{14} \\
\end{array}$ & 0.00042 \\
\hline & & $\begin{array}{c}\text { Sphingo- } \\
\text { monadales }\end{array}$ & $\begin{array}{c}\text { Sphingo- } \\
\text { monadaceae }\end{array}$ & Sphingomonas wittichii ${ }^{15}$ & 0.00005 \\
\hline & $\begin{array}{c}\text { Beta- } \\
\text { proteobacteria }\end{array}$ & Burkholderiales & $\begin{array}{l}\text { Comamona- } \\
\text { daceae }\end{array}$ & Variovorax paradoxus ${ }^{16}$ & 0.00068 \\
\hline & \multirow{2}{*}{$\begin{array}{c}\text { Gamma- } \\
\text { proteobacteria }\end{array}$} & \multirow[t]{2}{*}{ Pseudomonadales } & & Acinetobacter johnsonii $^{17}$ & 0.00005 \\
\hline & & & Moraxellaceae & $\begin{array}{c}\text { Acinetobacter } \\
\text { rhizosphaerae }\end{array}$ & 0.00003 \\
\hline $\begin{array}{l}\text { Verruco- } \\
\text { microbia }\end{array}$ & $\begin{array}{l}\text { Verruco- } \\
\text { microbiae }\end{array}$ & $\begin{array}{c}\text { Verruco- } \\
\text { microbiales }\end{array}$ & $\begin{array}{c}\text { Verruco- } \\
\text { microbiaceae }\end{array}$ & $\begin{array}{l}\text { Akkermansia } \\
\text { muciniphila }^{19}\end{array}$ & 0.00013 \\
\hline
\end{tabular}

Table 2: Summary of Bacteria Identified to the Species Level From 16S rRNA Gene-Based Metagenomic Study of Freshwater from a Verhniy Kaban Lake (2017)

${ }^{1}$ Aniline-assimilating bacteria. Found in the soil; human infection cases are known [10].

${ }^{2}$ Found in fresh and salt water [11].

${ }^{3}$ Obligate aerobe, widely distributed in the environment. Found in soils, dust, water, and air. Also is a part of the normal microflora of the surface of the skin of humans and mammals.

${ }^{4}$ Found on the skin and in the gastrointestinal tract of humans and animals. In humans, can cause skin diseases.

${ }^{5}$ The most common actinobacteria in the gastrointestinal tract of healthy people [12]

${ }^{6}$ Found in the human gastrointestinal tract [13].

${ }^{7}$ Found in the human gastrointestinal tract [14].

${ }^{8}$ Phosphite-assimilating bacteria isolated from the intestines of zooplankton Daphnia magna [15].

${ }^{9}$ Found in the gastrointestinal tract of animals [16].

${ }^{10}$ Isolated from gasoline-contaminated groundwater [17].

${ }^{11}$ One of the most common and important commensal bacteria of the human intestinal microbiota [18].

${ }^{12}$ Found in the gastrointestinal tract of humans [19] and birds [20].

${ }^{13}$ Found in the gastrointestinal tract of humans [21] and freshwater fish [22]

${ }^{14}$ Isolated from clinical samples of patients with cystic fibrosis. Used as a potential bioremediator of marine oil pollution [23].

${ }^{15}$ Isolated from fresh water [24].

${ }^{16}$ Found everywhere. Abundant in environments contaminated with organic compounds or heavy metals [25].

${ }^{17}$ Found in the environment as well as in the microbiome of animals. May colonize human skin and cause clinical infections [26].

${ }^{18}$ Isolated from plant rhizosphere [27].

${ }^{19}$ A type of human intestinal bacterium that decomposes mucin [28]. 


\section{Summary}

According to the results of the study using the next-generation sequencing method, the bacterial profile of Verhniy Kaban Lake for 2016-2017 was characterized. A comparative analysis of metagenomic data shows a significant change in bacterial diversity over the years.

A total of 110467 (2016) and 87093 (2017) high-quality reads were obtained; 100\% (2016) and 98\% (2017) of the bacterial population was classified to the phylum, while 95\% (2016) and 93\% (2017) was classified to the class level, $70 \%$ (2016) and 92\% (2017) was classified to the order level, 63\% (2016) and 69\% (2017) was classified to the family level, $29.80 \%$ (2016) and 32.08\% (2017) was classified to the genus level, and $0.43 \%$ (2017) was classified to the species level.

A total of 19 species of Bacteria were identified for Verhniy Kaban Lake, most of which are commonly found in the gastrointestinal tract of humans and/or animals are most common. These types of bacteria can pose a threat to human health. Therefore, the species composition of the bacterial community must be taken into account when assessing the ecological state of water reservoirs.

\section{Conclusions}

The obtained results are of great practical interest in monitoring of water reservoirs. The next-generation sequencing method can be successfully used to monitor water reservoirs in particular and to assess the ecological state of water reservoirs in general.

\section{Acknowledgments}

The work is performed according to the Russian Government Program of Competitive Growth of Kazan Federal University. The authors would like to thank Dr. S.Malanin and E.Boulygina, scientists of Kazan Federal University for their assistance with experimental work.

\section{References}

1. V.V. Kurilenko, O.V. Zaitseva, E.A. Novikova, N.G. Osmolovskaia, M.D. Ufimtseva, "Fundamentals of ecology, bioindication and biotesting of aquatic ecosystems", p. 448, 2003.

2. R.J.Newton, S.E.Jones, A.Eiler, K.D.McMahon, S.Bertilsson, «A Guide to the Natural History of Freshwater Lake Bacteria», Microbiol Mol Biol Rev., vol. 75(1), pp. 14-49, 2011.

3. S.Poirier, O.Rué, R.Peguilhan, G.Coeuret, M.Zagorec, M.Ch.Champomier-Vergès, V.Loux, S.Chaillou, «Deciphering intra-species bacterial diversity of meat and seafood spoilage microbiota using gyrB amplicon sequencing: A comparative analysis with 16S rDNA V3-V4 amplicon sequencing», PLoS One, vol. 13, e0204629, 2018.

4. A.Kharchenko, A.E.Sverdrup, L.L.Frolova, «The monitoring of Verhniy Kaban lake by rbcL gene of freshwater organisms using next-generation sequencing», International Journal of Green Pharmacy, 12 (3), pp. 756-762, 2018.

5. A.M.Husainov, L.L.Frolova «The ecological estimation of lake Verhniy Kaban using the next-generation sequencing», Indo American journal of pharmaceutical sciences (IAJPS), V.5 (10), pp. 10357-10363, 2018

6. J.Zhang, X.Ding, R.Guan, C.Zhu, C.Xu, B.Zhu, H.Zhang, Z.Xiong, Y.Xue, J.Tu, Z.Lu, «Evaluation of different 16S rRNA gene V regions for exploring bacterial diversity in a eutrophic freshwater lake», Sci Total Environ., vol. 618, pp. 1254-1267, 2018.

7. J.C.Ibal, H.Q.Pham, J.H.Shin, «Information about variations in multiple copies of bacterial 16S rRNA genes may aid in species identification», PLoS One, vol. 14, e0212090, 2019.

8. V.V. Bulion, "Methodological recommendations for collecting and processing materials in hydrobiological studies in freshwater. Phytoplankton and its products." - L.: GosNIORKh, p.32. 1981.

9. National Center for Biotechnology Information - http:/www.ncbi.nlm.nih.gov/

10. A.Y.M.Wang, J.F.W.Chan, C.C.Y.Yip, S.K.P.Lau, P.C.Y.Woo, K.Y.Yuen, «First Report of Human Infection by Agromyces mediolanus, a Gram-Positive Organism Found in Soil Siddharth Sridhar», J Clin Microbiol, vol. 53(10), pp. 3377-3379, 2015.

11. M.W.Hahn, «Description of seven candidate species affiliated with the phylum Actinobacteria, representing planktonic freshwater bacteria», Int J Syst Evol Microbiol., vol. 59, pp. 112-117, 2009.

12. S.Bag, T.S.Ghosh, B.Das, «Complete Genome Sequence of Collinsella aerofaciens Isolated from the Gut of a Healthy Indian Subject», Genome Announc., vol. 5 (47), pp. e01361-17, 2017.

13. A.Pianta, S.Arvikar, K.Strle, E.E.Drouin, Q.Wang, C.E.Costello, A.C. Steere, «Evidence for Immune Relevance of Prevotella copri, a Gut Microbe, in Patients with Rheumatoid Arthritis», Arthritis Rheumatol., vol. 69(5), pp. 964975, 2017.

14. H.Hayashi, K.Shibata, M.Sakamoto, S.Tomita, Y.Benno, «Prevotella copri sp. nov. and Prevotella stercorea sp. nov., isolated from human faeces», Int J Syst Evol Microbiol., vol. 57(Pt 5), pp. 941-946, 2007.

15. A.Poehlein, H.Najdenski, D.D.Simeonova, «Draft Genome Sequence of Flavobacterium succinicans Strain DD5b», Genome Announc., vol. 5(2), pp. e01492-16, 2017. 
16. M.Mohan, C.T.Chow, C.N.Ryan, L.S.Chan, J.Dufour, P.P.Aye, J.Blanchard, C.P.Moehs, K.Sestak, «Dietary Gluten-Induced Gut Dysbiosis Is Accompanied by Selective Upregulation of microRNAs with Intestinal Tight Junction and Bacteria-Binding Motifs in Rhesus Macaque Model of Celiac Disease», Nutrients., vol. 8(11), E684, 2016.

17. W.J.Robertson, J.P.Bowman, P.D.Franzmann, B.J.Mee, «Desulfosporosinus meridiei sp. nov., a spore-forming sulfate-reducing bacterium isolated from gasolene-contaminated groundwater», Int J Syst Evol Microbiol., vol. 51(Pt 1), pp. 133-140, 2001.

18. S.Bag, T.S.Ghosh, B.Das, «Complete Genome Sequence of Faecalibacterium prausnitzii Isolated from the Gut of a Healthy Indian Adult», Genome Announc., vol. 5(46), pp. e01286-17, 2017.

19. A.Schwiertz, G.L.Blay, M.Blaut, «Quantification of Different Eubacterium spp. in Human Fecal Samples with Species-Specific 16S rRNA-Targeted Oligonucleotide Probes», Appl Environ Microbiol., vol. 66(1), pp. 375-382, 2000.

20. C.DeMaesschalck, F.VanImmerseel, V.Eeckhaut, S.DeBaere, M.Cnockaert, S.Croubels, F.Haesebrouck, R.Ducatelle, P.Vandamme, «Faecalicoccus acidiformans gen. nov., sp. nov., isolated from the chicken caecum, and reclassification of Streptococcus pleomorphus (Barnes et al. 1977), Eubacterium biforme (Eggerth 1935) and Eubacterium cylindroides (Cato et al. 1974) as Faecalicoccus pleomorphus comb. nov., Holdemanella biformis gen. nov., comb. nov. and Faecalitalea cylindroides gen. nov., comb. nov., respectively, within the family Erysipelotrichaceae», Int J Syst Evol Microbiol., vol. 64(Pt 11), pp. 3877-3884, 2014.

21. S.M.Finegold, M.L.Vaisanen, D.R.Molitoris, T.J.Tomzynski, Y.Song, C.Liu, M.D.Collins, P.A.Lawson, «Cetobacterium somerae sp. nov. from human feces and emended description of the genus Cetobacterium», Syst Appl Microbiol., vol. 26(2), pp. 177-181, 2003.

22. C.Tsuchiya, T.Sakata, H.Sugita, «Novel ecological niche of Cetobacterium somerae, an anaerobic bacterium in the intestinal tracts of freshwater fish», Lett Appl Microbiol., vol. 46(1), pp. 43-48, 2008.

23. M.P.Ryan, J.T.Pembroke, «Brevundimonas spp: Emerging global opportunistic pathogens», Virulence, vol. 9(1), pp. 480-493, 2018.

24. Z.Ma, X.Shen, H.Hu, W.Wang, H.Peng, P.Xu, X.Zhang, «Genome sequence of Sphingomonas wittichii DP58, the first reported phenazine-1-carboxylic acid-degrading strain», J Bacteriol., vol. 194(13), pp. 3535-3536, 2012.

25. B.Satola, J.H.Wübbeler, A.Steinbüchel, «Metabolic characteristics of the species Variovorax paradoxus», Appl Microbiol Biotechnol., vol. 97(2), pp. 541-560, 2013.

26. S.Montaña, S.T.J.Schramm, G.M.Traglia, K.Chiem, G.P.D.Noto, M.Almuzara, C.Barberis, C.Vay, C.Quiroga, M.E.Tolmasky, A.Iriarte, M.S.Ramírez, «The Genetic Analysis of an Acinetobacter johnsonii Clinical Strain Evidenced the Presence of Horizontal Genetic Transfer», PLoS One., vol. 11(8), e0161528, 2016.

27. A. Gulati, P. Vyas, P. Rahi, R.C. Kasana, «Plant growth-promoting and rhizosphere-competent Acinetobacter rhizosphaerae strain BIHB 723 from the cold deserts of the Himalayas», Curr Microbiol., vol. 58(4), pp. 371-377, 2009.

28. W.M. deVos, «Microbe Profile: Akkermansia muciniphila: a conserved intestinal symbiont that acts as the gatekeeper of our mucosa», Microbiology, vol. 163(5), pp.646-648, 2017. 